\title{
Titanium dioxide nanoparticles oral exposure to pregnant rats and its distribution
}

\author{
Jinsoo Lee ${ }^{1,2}$, Ji-Seong Jeong1', Sang Yun Kim¹, Min-Kyu Park ${ }^{3}$, Sung-Deuk Choi ${ }^{3,4}$, Un-Jung Kim¹, Kwangsik Park ${ }^{5}$,
} Eun Ju Jeong ${ }^{1}$, Sang-Yoon Nam² and Wook-Joon Yü ${ }^{1 *}$

\begin{abstract}
Background: Titanium dioxide $\left(\mathrm{TiO}_{2}\right)$ nanoparticles are among the most manufactured nanomaterials in the industry, and are used in food products, toothpastes, cosmetics and paints. Pregnant women as well as their conceptuses may be exposed to $\mathrm{TiO}_{2}$ nanoparticles; however, the potential effects of these nanoparticles during pregnancy are controversial, and their internal distribution has not been investigated. Therefore, in this study, we investigated the potential effects of oral exposure to $\mathrm{TiO}_{2}$ nanoparticles and their distribution during pregnancy. $\mathrm{TiO}_{2}$ nanoparticles were orally administered to pregnant Sprague-Dawley rats (12 females per group) from gestation days (GDs) 6 to 19 at dosage levels of 0,100, 300 and $1000 \mathrm{mg} / \mathrm{kg} /$ day, and then cesarean sections were conducted on GD 20.
\end{abstract}

Results: In the maternal and embryo-fetal examinations, there were no marked toxicities in terms of general clinical signs, body weight, food consumption, organ weights, macroscopic findings, cesarean section parameters and fetal morphological examinations. In the distribution analysis, titanium contents were increased in the maternal liver, maternal brain and placenta after exposure to high doses of $\mathrm{TiO}_{2}$ nanoparticles.

Conclusion: Oral exposure to $\mathrm{TiO}_{2}$ during pregnancy increased the titanium concentrations in the maternal liver, maternal brain and placenta, but these levels did not induce marked toxicities in maternal animals or affect embryo-fetal development. These results could be used to evaluate the human risk assessment of $\mathrm{TiO}_{2}$ nanoparticle oral exposure during pregnancy, and additional comprehensive toxicity studies are deemed necessary considering the possibility of complex exposure scenarios and the various sizes of $\mathrm{TiO}_{2}$ nanoparticles.

Keywords: Titanium dioxide nanoparticles, Developmental toxicity, Maternal and fetal distribution, Nanotoxicity

\section{Introduction}

Nanotechnology is a rapidly growing field in recent decades and is widely applied in various areas of industry [1]. The use of nanotechnology extends to cosmetics, fabrics and clothing, personal care items, cleaning solutions, sporting equipment and electronics as well as toys for children [2, 3]. Nanomaterials comprise natural, incidental or manufactured material-containing particles with one or more external dimensions in the size range of $1 \mathrm{~nm}-100 \mathrm{~nm}$ [4]. The size-dependent properties of

\footnotetext{
* Correspondence: yuwj@kitox.re.kr

${ }^{1}$ Developmental and Reproductive Toxicology Research Group, Korea

Institute of Toxicology, Deajeon 34114, Republic of Korea

Full list of author information is available at the end of the article
}

nanomaterials increase the surface-to-interaction, the possibility of improper interactions with intracellular components and unusual electronic properties, such as electron donation or acceptance [5]. These characteristic properties raise concerns regarding the potential health risk to humans and livestock, as well as the environment $[6,7]$.

Titanium dioxide $\left(\mathrm{TiO}_{2}\right)$ nanoparticles are also widely used nanomaterials and are among the top five nanomaterials used in consumer products [8]. $\mathrm{TiO}_{2}$ nanoparticles are used in paints, coatings, plastics, papers, inks, medicines, pharmaceuticals, food products, cosmetics and toothpastes [9-11]. The constant use of $\mathrm{TiO}_{2}$ nanoparticle-containing products increases the possibility of chronic exposure and accumulation in the

(c) The Author(s). 2019 Open Access This article is distributed under the terms of the Creative Commons Attribution 4.0 International License (http://creativecommons.org/licenses/by/4.0/), which permits unrestricted use, distribution, and 
internal organs of humans. In particular, oral and respiratory exposures are considered the most prevalent exposure routes to humans [12]. Oral exposure is an important route for absorption because water, liquid beverages and drug carriers may contain $\mathrm{TiO}_{2}$ nanoparticles [13]. When $\mathrm{TiO}_{2}$ nanoparticles $(25,80$, and 155 $\mathrm{nm} ; 5 \mathrm{~g} / \mathrm{kg}$; single oral dose in mice) enter the circulatory system via oral exposure, they are retained in the internal organs [14].

Several toxicity studies with $\mathrm{TiO}_{2}$ nanoparticles have been recently conducted; however, there is little toxicological information on $\mathrm{TiO}_{2}$ nanoparticle exposure during pregnancy. Shimizu et al [15] reported that subcutaneous exposure to $\mathrm{TiO}_{2}$ nanoparticles $(2570 \mathrm{~nm}$; $100 \mu \mathrm{l}$ suspended at $1 \mu \mathrm{g} / \mu \mathrm{l}$ ) during gestation (gestation days [GDs] 6, 9, 12 and 15) in ICR mice induced changes in gene expression related to brain development, cell death, response to oxidative stress, and mitochondria in the brain during the prenatal period. Takeda et al. [16] reported that subcutaneous exposure of ICR mice to $\mathrm{TiO}_{2}$ nanoparticles (25 and $70 \mathrm{~nm} ; 16 \mathrm{mg} / \mathrm{kg}$ ) during gestation (GDs 3, 7, 10 and 14) induced postnatal reproductive toxicities in male offspring, including disrupted seminiferous tubules and tubule lumens with few mature sperm, decreased sperm production and epididymis sperm motility. In addition, $\mathrm{TiO}_{2}$ nanoparticles were detected in cells of the olfactory bulb and cerebral cortex in these postnatal animals. These previous studies indicated that $\mathrm{TiO}_{2}$ nanoparticle exposure during pregnancy is able to induce toxic effects. However, the opposite result was also reported: oral exposure of six types of $\mathrm{TiO}_{2}$ particles, including pigment grade and nanoscale (42, 43, 47, 153, 195 and $213 \mathrm{~nm} ; 100,300$, and $1000 \mathrm{mg} / \mathrm{kg}$; daily, beginning on GDs 6 through 20 in rats), did not induce maternal and embryo-fetal developmental toxicities [17].

The objective of this study was to confirm the maternal and embryo-fetal toxicities of orally exposed $\mathrm{TiO}_{2}$ nanoparticles during pregnancy. In addition, we also analyzed the internal concentration of titanium in maternal and fetal tissues. The results of this study will contribute to elucidating the potential effects of $\mathrm{TiO}_{2}$ nanoparticles on humans and support the accurate risk assessment of these nanoparticles at different sizes and under complex exposure scenarios.

\section{Materials and methods}

\section{$\mathrm{TiO}_{2}$ nanoparticles and physicochemical characterization}

$\mathrm{TiO}_{2}$ nanoparticles were obtained from Evonik Industries (Germany) as a fine white powder with a hydrophilic characteristic caused by hydroxyl groups on the surface. The nanoparticles consisted of aggregated primary particles; the mean diameter of the primary particle was approximately $21 \mathrm{~nm}$, and the weight ratio of anatase/rutile was approximately $80 / 20$ according to the manufacturer's information.

Physicochemical characterization of $\mathrm{TiO}_{2}$ nanoparticles was confirmed with an additional analytical method. The primary particle size and morphology were analyzed by a transmission electron microscope (JEM-2100F, JEOL, Japan) operating at $200 \mathrm{kV}$. $\mathrm{TiO}_{2}$ NPs for transmission electron microscope (TEM) analysis were deposited on carbon-coated nickel mesh grids and were air-dried overnight before analysis. The purity was also analyzed with energy-dispersive X-ray (EDX) analysis on the same TEM images (JEM-2100F TEM equipped with an X-Max ${ }^{\mathrm{N}} 150 \mathrm{~mm}^{2}$ silicon drift detector, Oxford Instruments, UK). The average primary particle size was calculated by measuring at least 100 particles using an image analyzer program (DigitalMicrograph, Gatan Inc., USA). The hydrodynamic diameter and zeta potential of $\mathrm{TiO}_{2}$ nanoparticles in deionized water $(10 \mathrm{mg} / \mathrm{ml}$ concentration) were analyzed by the dynamic light scattering (DLS) method (ELS-8000, Otsuka Electronics, Japan).

\section{Animals and experimental design}

Nine-week-old specific pathogen free (SPF) female Sprague-Dawley rats were obtained (Orient Bio Inc., Republic of Korea) and permitted a 5-days period of acclimation to the animal room environment. Females were selected for mating on the basis of adequate body weight and freedom from clinical signs of disease or injuries during the acclimation period. Females were mated by placement in the cage of a male that was maintained only for mating without any treatment. Sixty-four mating-proven female rats were selected for this study. The day of sperm and/or vaginal plugs detection was designated as day 0 of gestation. Pregnancy was determined by confirmation of implantation sites on the uterus at the time of final sacrifice.

The animal room environment was automatically controlled according to institutional criteria (target range: temperature of $23 \pm 3{ }^{\circ} \mathrm{C}$, relative humidity of $30-70 \%$, approximately 12-h light cycle with 150-300 Lux, and ventilation at 10-20 times/hour). A standard rodent pellet diet irradiated by gamma-ray (PMI Nutrition International, USA) was provided to the animals ad libitum. Titanium was not detected in the rodent pellet diet according to the chemical composition results from the supplier. The animals had ad libitum access to filtered, ultraviolet light-irradiated municipal tap water at all times. Aspen animal bedding material (Bio Lab, Republic of Korea) was sterilized and then provided to the animals in each cage. There were no known contaminants in the food, water and bedding at levels that would be expected to interfere with the results of the study. 
$\mathrm{TiO}_{2}$ nanoparticles were suspended in deionized water for administration via the gastrointestinal route. To obtain a homogenized suspension, the dosing formulation was continuously stirred with a magnetic stirrer during the dosing procedure. $\mathrm{TiO}_{2}$ nanoparticles were administered by oral gavage to mated females to evaluate the potential maternal and embryo-fetal development toxicity of $\mathrm{TiO}_{2}$ nanoparticles. This study design refers to the OECD Guideline 414 (Prenatal Developmental Toxicity Study) [18] and was carried out in a good laboratory practice (GLP) facility but was not conducted within the scope of GLP regulations. In addition, we also analyzed the internal distribution of titanium in maternal and fetal tissues after repeated oral exposure during pregnancy. Twelve females per group in the toxicology group (total 48 females) and 4 females per group in the tissue distribution group (total 16 females) were used in this study. $\mathrm{TiO}_{2}$ nanoparticles were administered daily by oral gavage from GDs 6 to 19 at dose levels of 0,100 , 300 and $1000 \mathrm{mg} / \mathrm{kg}$ with a dose volume of $10 \mathrm{~mL} / \mathrm{kg}$.

All procedures with animals were in compliance with the Animal Protection Act of Korea and the Guide for the Care and Use of Laboratory Animals published by the Institute for Laboratory Animal Research (ILAR). The Korea Institute of Toxicology (KIT) received full accreditation from the Association for Assessment and Accreditation of Laboratory Animal Care International (AAALAC International) in 1998, which has been renewed regularly. This study was reviewed and assessed by the Institutional Animal Care and Use Committee (IACUC) of KIT.

\section{In-life maternal examinations}

A mortality observation was conducted twice daily (once at the start of the animal room procedure and once at the end of the animal room procedure). Observation of general clinical signs, including general appearance and behavioral changes, were conducted twice a day during the treatment period (before and after dosing) and once a day during the nontreatment period. During pregnancy, maternal animals were especially monitored for signs of abortion or premature delivery. Body weights and food consumption were measured individually on GDs $0,6,9,12,15,17$ and 20 .

\section{Cesarean section and fetal morphological examinations}

On GD 20, all toxicology group females were euthanized using $\mathrm{CO}_{2}$ gas for macroscopic observation and cesarean section. All females were examined carefully for external, abdominal, thoracic and cranial cavity abnormalities. Special attention was paid to the organs of the reproductive system. Gravid uteri were retrieved and then weighed to calculate the corrected terminal weight (body weight on GD 20 minus gravid uterine weight) and the net body weight change (corrected terminal weight minus body weight on GD 6). The corpora lutea, implantation sites, live/dead fetuses and resorptions (early or late) were counted or measured, and then calculated pre-implantation loss, post-implantation loss and fetal death. Each live fetus was weighed and sexed. In addition, each placenta was weighed and examined macroscopically.

Fetal morphological examinations, including external, visceral and skeletal examinations, were conducted. Fetuses were numbered from the left uterine horn to the right uterine horn. Alternate fetuses were selected for either skeletal or visceral examination (odd numbers: skeletal examination, even numbers: visceral examination). Live fetuses retrieved from gravid uteri were examined immediately to evaluate external abnormalities. For fetal visceral examinations, fetuses were fixed with Bouin's solution, and then modified Wilson's method [19] for the head, Nishimura's method [20] for the thorax and Staples's method [21] for the abdomen were used. For skeletal examinations, fetuses were fixed with $70 \%$ ethanol, and then Dawson's method [22] was used after staining with alizarin red. Fetal morphological abnormalities were classified as malformation or variations according to the severity of findings. In addition, we used the terminology suggested in an internationally developed glossary of terms for structural developmental abnormalities in common laboratory mammals [23].

\section{Tissue collection and preprocessing}

On GD 20, all tissue-distribution group females were euthanized using $\mathrm{CO}_{2}$ gas to conduct the tissue collection. Maternal tissue collection (approximately $200 \mathrm{mg}$ each), including liver (middle lobe), brain, and blood, was conducted. Fetal tissue collection (approximately $200 \mathrm{mg}$ each), including liver, brain, blood and placenta, was conducted. At least 3 fetuses from a litter were used for fetal tissue collection, and collected samples were pooled by a litter. All collected samples were weighed to quantitatively calculate the tissue distribution and then maintained in frozen condition (approximately $-80^{\circ} \mathrm{C}$ ) until titanium content analysis.

For the evaluation of tissue levels of titanium, the samples were digested with a tri-acid mixture. The tri-acid mixture was prepared with concentrated hydrofluoric acid (HF, 49\%, J.T. Baker, USA), nitric acid $\left(\mathrm{HNO}_{3}, 60 \%\right.$, Matsunoen Chemical LTD, Japan), and hydrogen peroxide $\left(\mathrm{H}_{2} \mathrm{O}_{2}, 30 \%\right.$, J.T. Baker, USA) mixed in a ratio of 1:4: 1 , and $12 \mathrm{~mL}$ of this mixture was added to each Teflon reaction vessel containing a sample [24-26]. Thereafter, the samples with mixed acid were heated on a graphite digestion system (ODLAB, OD-98-002P, Republic of Korea) for $1 \mathrm{~h}$, and digested residues were made up to 
$10 \mathrm{~mL}$ with $1 \%(\mathrm{v} / \mathrm{v}) \mathrm{HNO}_{3}(\mathrm{pH}=1-2)$. The final samples were stored at $-4{ }^{\circ} \mathrm{C}$ before analysis.

\section{Titanium distribution analysis}

Inductively coupled plasma mass spectrometry (ICPMS, ELAN DRC II, Canada) was used to measure titanium concentrations in the collected samples. Instrumental operating conditions were as follows: $1500 \mathrm{~W}$ of radiofrequency $(\mathrm{RF})$ power, $0.9 \mathrm{~L} / \mathrm{min}$ of nebulizer gas flow rate, and $1.5 \mathrm{~L} / \mathrm{min}$ of auxiliary gas flow rate. Calibration standards of $1,5,10,20$, and $40 \mu \mathrm{g} / \mathrm{L}$ for titanium $(1000 \mathrm{mg} / \mathrm{L}$, Merck, Germany) were used, and coefficients of determination $\left(R^{2}\right)$ for titanium were higher than 0.999. Blank samples, which consisted of solutions without the presence of tissue, were used for the assessment of contamination during the experiments. The digestion method was applied to blank samples in order to measure the likely amounts of titanium contamination. Teflon tubes, $15 \mathrm{~mL}$ polypropylene tubes, and chemicals were all potential sources of titanium contamination [26]. For instrumental detection limits (IDLs), $1 \mathrm{~mL}$ of the lowest level of calibration standard $(1 \mu \mathrm{g} / \mathrm{L})$ was injected into the ICP-MS seven times $(n=$ 7 ), and a standard deviation of analytical data was multiplied by a Student's $t$ value of 3.14. For method detection limits (MDLs) and the limit of quantification (LOQ), 2 $\mathrm{mL}$ of $5 \mu \mathrm{g} / \mathrm{L}$ standard was spiked into the seven blank samples, and standard deviations were multiplied by 3.14 and 10, respectively. The final volume in each blank sample was $10 \mathrm{~mL}$. ICP-MS was sensitive enough to quantify all of our samples, and there was no need to improve the IDL of $0.038 \mu \mathrm{g} / \mathrm{L}$. The MDLs and LOQ for the collected samples were determined to be $0.0001 \mathrm{mg} /$ $\mathrm{kg}$ and $0.0002 \mathrm{mg} / \mathrm{kg}$, respectively. The values presented high sensitivity and a satisfactory recovery rate $(96.5 \pm$ $2.4 \%)$. Maternal samples for non-pregnant subjects were excluded from the concentration analysis, and two samples (one fetal blood at vehicle control and one maternal liver at $100 \mathrm{mg} / \mathrm{kg}$ ) were excluded from the concentration analysis because they were considered to be contaminated.

\section{Statistical analysis}

Statistical analyses for comparisons of the various dose groups with the vehicle control group were conducted using the Pristima System (Version 7.2, Xybion Medical System Co., USA) or SAS/STAT (Version 9.4, SAS Institute Inc., USA). Litter data were statistically evaluated using the litter as a statistical unit. Multiple comparison tests for different dose groups were conducted. Continuous data were examined for variance in homogeneity using Bartlett's Test. Homogeneous data were analyzed using analysis of variance (ANOVA), and the significance of intergroup differences was analyzed using
Dunnett's test. Heterogeneous data were analyzed using the Kruskal-Wallis test, and the significance of intergroup differences between the control and treated groups was assessed using Dunn's rank sum test. Oneway analysis of covariance (ANCOVA) was used to analyze fetal and placental weight data. The litter size was used as the covariate.

\section{Results \\ Physicochemical characterization of $\mathrm{TiO}_{2}$ nanoparticles}

The physicochemical characterization of $\mathrm{TiO}_{2}$ nanoparticles, including analyses of primary shape, primary size, purity, hydrodynamic size and zeta potential, is summarized in Table 1 . The majority of the $\mathrm{TiO}_{2}$ nanoparticles had spherical and anatase crystal shapes with a purity of $100 \%$. The mean primary size of the $\mathrm{TiO}_{2}$ nanoparticles was $17.8 \pm 5.46 \mathrm{~nm}$. The hydrodynamic size of the $\mathrm{TiO}_{2}$ nanoparticles was $341.5 \mathrm{~nm}$, which indicates that $\mathrm{TiO}_{2}$ nanoparticles were prone to aggregation and formed a larger size in the vehicle. The zeta potential of the $\mathrm{TiO}_{2}$ nanoparticles in the vehicle was $35.16 \mathrm{mV}$.

\section{Mortality and general clinical sign observation}

All female rats survived through the end of the study, and no abnormal general clinical signs were observed in any group throughout the study.

\section{Body weights and food consumption}

No test item-related changes in body weight and body weight gain were observed during the study period (Table 2). For food consumption, a statistically significant decrease during the study period ( $92 \%$ of control) at $1000 \mathrm{mg} / \mathrm{kg}$ was considered test item-related (Table 3). However, this decrease did not have toxicological relevance since it was minimal and there was no correlated decreased body weight or body weight gain during the study period.

\section{Organ weights and gravid uterine weight}

There was no test item-related change in absolute and relative organ weights in this study (Table 4). In addition, there was no test item-related change in gravid uterine weight, corrected terminal body weight (body weight on GD 20 minus gravid uterine weight) and net body weight change (corrected terminal body weight minus body weight on GD 6) in this study (Table 5).

\section{Cesarean section and fetal morphological examinations}

There was no test item-related change in cesarean section parameters, including corpora lutea, implantation, resorptions (early and late), dead and live fetuses, sex ratio, pre-implantation loss, post-implantation loss, fetal weight, placental weight and placental macroscopic observation (Table 6). In addition, there 
Table 1 Physicochemical characterization of titanium dioxide nanoparticles

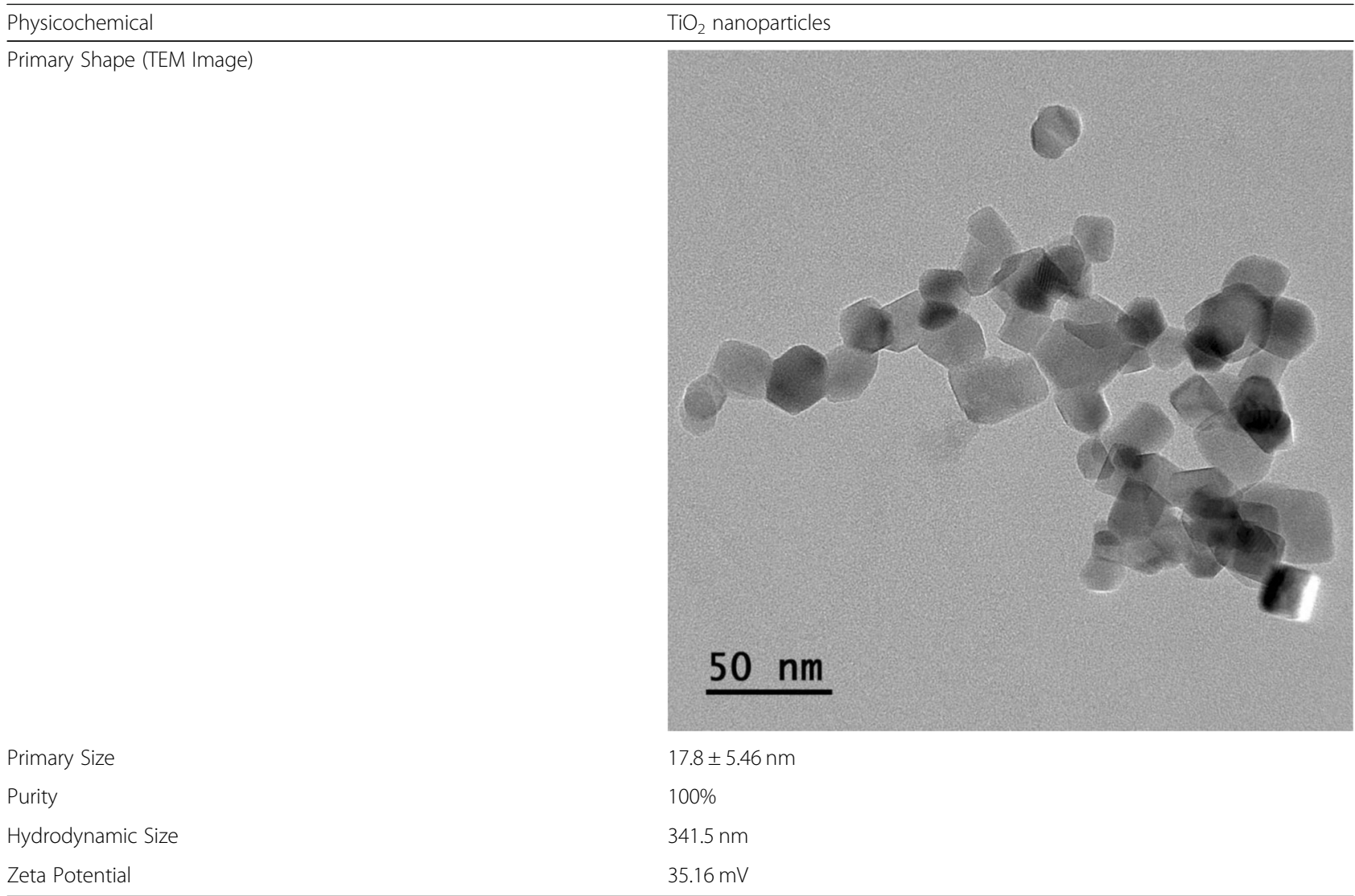

was no test item-related change in the fetal external and visceral examinations (Table 7). In the skeletal examination, an increased ossification site of metatarsals in both hindlimbs was only observed at $100 \mathrm{mg} /$ $\mathrm{kg}$, but it was considered incidental since it did not have a dose response and there were no changes in other related parameters (Table 8).

\section{$\mathrm{TiO}_{2}$ nanoparticle distribution in tissues}

The titanium contents were analyzed in maternal tissues (liver, brain and blood) and fetal tissues (liver, brain, blood and placenta) after the oral exposure of $\mathrm{TiO}_{2}$ nanoparticles during pregnancy (Fig. 1). Titanium concentrations in maternal liver, maternal brain and placenta at $1000 \mathrm{mg} / \mathrm{kg}$ were elevated compared to the

Table 2 Body weights and body weight gain of $\mathrm{TiO}_{2}$ nanoparticles exposed pregnant females during the pregnancy

\begin{tabular}{|c|c|c|c|c|}
\hline & \multicolumn{4}{|c|}{$\mathrm{TiO}_{2}$ nanoparticles $(\mathrm{mg} / \mathrm{kg})$} \\
\hline & 0 & 100 & 300 & 1000 \\
\hline Pregnant Females (N) & 12 & 12 & 12 & 12 \\
\hline \multicolumn{5}{|l|}{ Body Weight (g) } \\
\hline Gestation day 0 & $235.4 \pm 8.88^{\mathrm{a}}$ & $235.4 \pm 8.93$ & $235.6 \pm 9.19$ & $235.5 \pm 9.70$ \\
\hline Gestation day 6 & $275.5 \pm 12.08$ & $277.4 \pm 11.41$ & $274.5 \pm 10.31$ & $276.8 \pm 13.64$ \\
\hline Gestation day 9 & $288.1 \pm 13.17$ & $288.4 \pm 12.59$ & $286.6 \pm 9.74$ & $286.7 \pm 14.86$ \\
\hline Gestation day 12 & $307.5 \pm 14.00$ & $307.3 \pm 13.20$ & $307.6 \pm 10.38$ & $306.3 \pm 18.14$ \\
\hline Gestation day 15 & $323.5 \pm 15.19$ & $325.8 \pm 15.92$ & $326.7 \pm 12.20$ & $321.0 \pm 19.40$ \\
\hline Gestation day 17 & $342.8 \pm 17.30$ & $346.9 \pm 16.35$ & $349.2 \pm 11.13$ & $341.4 \pm 18.53$ \\
\hline Gestation day 20 & $389.3 \pm 26.47$ & $399.1 \pm 22.46$ & $400.1 \pm 14.68$ & $388.7 \pm 21.15$ \\
\hline \multicolumn{5}{|l|}{ Body Weight Gain (g) } \\
\hline Gestation day 6-20 (treatment period) & $113.8 \pm 16.81$ & $121.7 \pm 15.08$ & $125.6 \pm 9.16$ & $111.9 \pm 10.30$ \\
\hline
\end{tabular}

Values are presented as mean \pm S.D 
Table 3 Food consumption of $\mathrm{TiO}_{2}$ nanoparticles exposed pregnant females during the pregnancy

\begin{tabular}{|c|c|c|c|c|}
\hline & \multicolumn{4}{|c|}{$\mathrm{TiO}_{2}$ nanoparticles $(\mathrm{mg} / \mathrm{kg}$ ) } \\
\hline & 0 & 100 & 300 & 1000 \\
\hline Pregnant Females (N) & 12 & 12 & 12 & 12 \\
\hline \multicolumn{5}{|l|}{ Food Consumption (g) } \\
\hline Gestation day 0-6 & $24.3 \pm 2.70^{a)}$ & $23.3 \pm 1.95$ & $24.0 \pm 2.00$ & $22.9 \pm 1.55$ \\
\hline Gestation day 6-9 & $26.0 \pm 2.60$ & $25.4 \pm 1.97$ & $25.7 \pm 1.44$ & $23.7 \pm 1.77^{*}$ \\
\hline Gestation day 9-12 & $26.6 \pm 2.84$ & $24.8 \pm 1.50$ & $26.0 \pm 1.35$ & $23.5 \pm 2.70$ \\
\hline Gestation day $12-15$ & $26.0 \pm 2.19$ & $25.6 \pm 2.22$ & $26.2 \pm 1.70$ & $24.1 \pm 2.38$ \\
\hline Gestation day $15-17$ & $27.1 \pm 1.92$ & $26.9 \pm 2.37$ & $28.0 \pm 2.12$ & $25.6 \pm 2.52$ \\
\hline Gestation day $17-20$ & $27.7 \pm 2.43$ & $27.1 \pm 2.02$ & $28.5 \pm 2.05$ & $26.2 \pm 2.10$ \\
\hline Gestation day 6-20 (treatment period) & $26.7 \pm 2.15$ & $25.9 \pm 1.73$ & $26.8 \pm 1.39$ & $24.5 \pm 2.04 * *$ \\
\hline
\end{tabular}

${ }^{a}$ Values are presented as mean \pm S.D

**Significant difference at $p<0.01$ level compared with the control group

concentration in control animals. In addition, at $300 \mathrm{mg} /$ $\mathrm{kg}$, titanium concentrations in the maternal brain and placenta were also slightly elevated. Moreover, there was no titanium concentration change in the maternal blood, fetal liver, fetal brain or fetal blood.

\section{Discussion and conclusion}

Oral exposure to $\mathrm{TiO}_{2}$ nanoparticles is one of the most prevalent exposure scenarios because humans are frequently exposed to $\mathrm{TiO}_{2}$ nanoparticles contained in food products, liquid beverages and drugs [27, 28]. In this study, we evaluated the potential effects of oral exposure to $\mathrm{TiO}_{2}$ nanoparticles during pregnancy and their distribution in maternal organs as well as fetuses. $\mathrm{TiO}_{2}$ nanoparticles were administered by oral gavage to pregnant Sprague-Dawley rats at doses of 0, 100, 300 and $1000 \mathrm{mg} / \mathrm{kg}$. In-life and terminal experimental endpoints, including general clinical signs, body weight

Table 4 Absolute and relative organ weights of $\mathrm{TiO}_{2}$ nanoparticles exposed pregnant females

\begin{tabular}{|c|c|c|c|c|}
\hline & \multicolumn{4}{|c|}{$\mathrm{TiO}_{2}$ nanoparticles $(\mathrm{mg} / \mathrm{kg})$} \\
\hline & $\overline{0}$ & 100 & 300 & 1000 \\
\hline Pregnant Females (N) & 12 & 12 & 12 & 12 \\
\hline Adrenal glands (g) & $0.08 \pm 0.010^{\mathrm{a}}$ & $0.07 \pm 0.010$ & $0.07 \pm 0.010$ & $0.07 \pm 0.009$ \\
\hline Organ to terminal body weight ratio (\%) & $0.02 \pm 0.003$ & $0.02 \pm 0.003$ & $0.02 \pm 0.003$ & $0.02 \pm 0.002$ \\
\hline Brain (g) & $1.86 \pm 0.080$ & $1.87 \pm 0.089$ & $1.83 \pm 0.064$ & $1.90 \pm 0.045$ \\
\hline Organ to terminal body weight ratio (\%) & $0.49 \pm 0.047$ & $0.49 \pm 0.037$ & $0.47 \pm 0.021$ & $0.50 \pm 0.024$ \\
\hline Heart (g) & $1.09 \pm 0.106$ & $1.10 \pm 0.087$ & $1.12 \pm 0.066$ & $1.10 \pm 0.103$ \\
\hline Organ to terminal body weight ratio (\%) & $0.29 \pm 0.028$ & $0.28 \pm 0.026$ & $0.29 \pm 0.018$ & $0.29 \pm 0.026$ \\
\hline Kidneys (g) & $2.05 \pm 0.211$ & $2.03 \pm 0.160$ & $2.06 \pm 0.189$ & $2.06 \pm 0.192$ \\
\hline Organ to terminal body weight ratio (\%) & $0.54 \pm 0.049$ & $0.52 \pm 0.034$ & $0.53 \pm 0.047$ & $0.55 \pm 0.050$ \\
\hline Liver (g) & $14.19 \pm 1.000$ & $14.48 \pm 1.039$ & $15.16 \pm 1.186$ & $14.70 \pm 0.823$ \\
\hline Organ to terminal body weight ratio (\%) & $3.75 \pm 0.229$ & $3.75 \pm 0.185$ & $3.89 \pm 0.237$ & $3.88 \pm 0.138$ \\
\hline Pituitary gland (g) & $0.01 \pm 0.002$ & $0.01 \pm 0.003$ & $0.01 \pm 0.002$ & $0.01 \pm 0.002$ \\
\hline Organ to terminal body weight ratio (\%) & $0.004 \pm 0.0006$ & $0.004 \pm 0.0006$ & $0.004 \pm 0.0005$ & $0.004 \pm 0.0005$ \\
\hline Spleen (g) & $0.70 \pm 0.116$ & $0.69 \pm 0.073$ & $0.73 \pm 0.115$ & $0.71 \pm 0.077$ \\
\hline Organ to terminal body weight ratio (\%) & $0.19 \pm 0.028$ & $0.18 \pm 0.018$ & $0.19 \pm 0.028$ & $0.19 \pm 0.019$ \\
\hline Lung & $1.35 \pm 0.105$ & $1.33 \pm 0.112$ & $1.35 \pm 0.122$ & $1.28 \pm 0.107$ \\
\hline Organ to terminal body weight ratio (\%) & $0.36 \pm 0.032$ & $0.35 \pm 0.034$ & $0.35 \pm 0.030$ & $0.34 \pm 0.021$ \\
\hline Right ovary (g) & $0.06 \pm 0.012$ & $0.07 \pm 0.01$ & $0.06 \pm 0.011$ & $0.06 \pm 0.011$ \\
\hline Organ to terminal body weight ratio (\%) & $0.02 \pm 0.003$ & $0.02 \pm 0.003$ & $0.02 \pm 0.003$ & $0.02 \pm 0.003$ \\
\hline Left ovary (g) & $0.06 \pm 0.009$ & $0.06 \pm 0.011$ & $0.06 \pm 0.014$ & $0.06 \pm 0.012$ \\
\hline Organ to terminal body weight ratio (\%) & $0.02 \pm 0.002$ & $0.01 \pm 0.003$ & $0.02 \pm 0.004$ & $0.02 \pm 0.003$ \\
\hline Thymus (g) & $0.40 \pm 0.084$ & $0.37 \pm 0.076$ & $0.43 \pm 0.066$ & $0.37 \pm 0.080$ \\
\hline Organ to terminal body weight ratio (\%) & $0.11 \pm 0.023$ & $0.10 \pm 0.019$ & $0.11 \pm 0.0175$ & $0.10 \pm 0.023$ \\
\hline
\end{tabular}

Values are presented as mean \pm S.D 
Table 5 Gravid uterine weight, corrected terminal weight and net body weight change of $\mathrm{TiO}_{2}$ nanoparticles exposed pregnant females during the pregnancy

\begin{tabular}{|c|c|c|c|c|}
\hline & $\mathrm{TiO}_{2}$ nanopartic & & & \\
\hline & 0 & 100 & 300 & 1000 \\
\hline Pregnant Females (N) & 12 & 12 & 12 & 12 \\
\hline Gravid uterine weight (g) & $76.91 \pm 21.44^{\mathrm{a}}$ & $89.31 \pm 15.33$ & $81.92 \pm 6.91$ & $78.37 \pm 13.18$ \\
\hline Corrected terminal body weight $(\mathrm{g})^{\mathrm{b}}$ & $312.37 \pm 16.87$ & $309.78 \pm 16.54$ & $318.14 \pm 12.20$ & $310.37 \pm 20.59$ \\
\hline Net body weight change $(g)^{c}$ & $36.88 \pm 11.43$ & $32.40 \pm 8.89$ & $43.69 \pm 8.34$ & $33.54 \pm 10.82$ \\
\hline
\end{tabular}

aalues are presented as mean \pm S.D

${ }^{b}$ Body weight on GD 20 - Gravid uterine weight

${ }^{\mathrm{c} C o r r e c t e d ~ t e r m i n a l ~ b o d y ~ w e i g h t ~-~ B o d y ~ w e i g h t ~ o n ~ G D ~} 6$

changes, food consumption, macroscopic findings, organ weights, cesarean section parameters and fetal morphology, including external, visceral, and skeletal aspects, were examined. There were no $\mathrm{TiO}_{2}$ nanoparticle-related toxicological findings related to maternal and embryo-fetal development toxicity parameters during the study. In addition, increased titanium concentrations in the maternal liver, maternal brain and placenta were observed after high dose oral exposure during pregnancy.

The molecular mechanism of $\mathrm{TiO}_{2}$ nanoparticle-induced toxicity is regarded as the induction of inflammation and generation of reactive oxygen species (ROS). The accumulation of $\mathrm{TiO}_{2}$ nanoparticles induces chronic inflammation, which leads to the formation of ROS and cell proliferation [29]. Previous studies have demonstrated that $\mathrm{TiO}_{2}$ nanoparticle exposure induces the expression of inflammatory cytokines, including IL-1a, IL-1b, IL-2, IL-4, IL-6 and IL-18 [30-32]. In addition, the role of free radicals in DNA damage [27, 33], ROSinduced activation of p53-mediated DNA damage [28] and cell-derived oxidants involved in the induction of mutagenesis [34] after $\mathrm{TiO}_{2}$ nanoparticle exposure were investigated. Although the exact pathophysiological mechanism is not clear, these multifactorial events related to the induction of inflammation leading to the production of ROS would be the major cause in $\mathrm{TiO}_{2}$ nanoparticle-induced toxicity.

Experimental animal studies were also conducted to evaluate the potential effects of $\mathrm{TiO}_{2}$ nanoparticle exposure. An acute oral toxicity study in mice $(25,80$ and $155 \mathrm{~nm}, 5000 \mathrm{mg} / \mathrm{kg}$ ) reported no obvious acute toxicity, but hepatic and renal injury was observed in the

Table 6 Caesarean section results of $\mathrm{TiO}_{2}$ nanoparticles exposed pregnant females during the pregnancy

\begin{tabular}{|c|c|c|c|c|}
\hline & \multicolumn{4}{|c|}{$\mathrm{TiO}_{2}$ nanoparticles $(\mathrm{mg} / \mathrm{kg})$} \\
\hline & 0 & 100 & 300 & 1000 \\
\hline Pregnant Females (N) & 12 & 12 & 12 & 12 \\
\hline Corpora lutea (N) & $14.1 \pm 1.83^{\mathrm{a}}$ & $14.6 \pm 1.98$ & $13.9 \pm 1.31$ & $14.1 \pm 1.56$ \\
\hline Implantation (N) & $12.8 \pm 3.81$ & $14.4 \pm 2.19$ & $13.6 \pm 1.38$ & $13.2 \pm 2.55$ \\
\hline Early resorptions (N) & $0.4 \pm 0.67$ & $0.2 \pm 0.58$ & $0.4 \pm 0.67$ & $0.4 \pm 0.67$ \\
\hline Late resorptions (N) & $0.0 \pm 0.00$ & $0.2 \pm 0.39$ & $0.0 \pm 0.00$ & $0.0 \pm 0.00$ \\
\hline Dead fetuses $(\mathrm{N})$ & $0.0 \pm 0.00$ & $0.0 \pm 0.00$ & $0.0 \pm 0.00$ & $0.0 \pm 0.00$ \\
\hline Fetal death (resorptions + dead fetuses) & $0.4 \pm 0.67$ & $0.3 \pm 0.65$ & $0.4 \pm 0.67$ & $0.4 \pm 0.67$ \\
\hline Live fetuses (N) & $12.4 \pm 3.55$ & $14.1 \pm 2.54$ & $13.2 \pm 1.34$ & $12.8 \pm 2.45$ \\
\hline Sex ratio (\%, male) & $48.1 \pm 18.87$ & $63.0 \pm 14.98$ & $45.2 \pm 7.01$ & $53.7 \pm 13.75$ \\
\hline Pre-implantation loss $(\%)^{b}$ & $10.0 \pm 22.13$ & $1.4 \pm 3.19$ & $2.4 \pm 3.57$ & $7.0 \pm 12.07$ \\
\hline Post-implantation loss $(\%)^{c}$ & $2.7 \pm 4.31$ & $2.7 \pm 5.98$ & $3.0 \pm 4.65$ & $3.0 \pm 5.18$ \\
\hline Fetal weight (g) & $4.24 \pm 0.25$ & $4.38 \pm 0.30$ & $4.23 \pm 0.25$ & $4.21 \pm 0.25$ \\
\hline Covariate adjusted means & 4.22 & 4.40 & 4.23 & 4.20 \\
\hline Placental weight (g) & $0.50 \pm 0.06$ & $0.49 \pm 0.05$ & $0.54 \pm 0.14$ & $0.49 \pm 0.05$ \\
\hline Covariate adjusted means & 0.49 & 0.49 & 0.54 & 0.49 \\
\hline Placental macroscopic observation & NAD & NAD & NAD & NAD \\
\hline
\end{tabular}

NAD No Abnormalities Detected

${ }^{a}$ Values are presented as mean \pm S.D

${ }^{b}$ [(No. of corpora lutea - No. of implantation) / No. of corpora lutea $] \times 100$

[ $[$ (No. of implantation - No. of live fetuses) $/$ No. of implantation $] \times 100$ 
Table 7 Fetal external and visceral examination results of $\mathrm{TiO}_{2}$ nanoparticles exposed pregnant females during the pregnancy

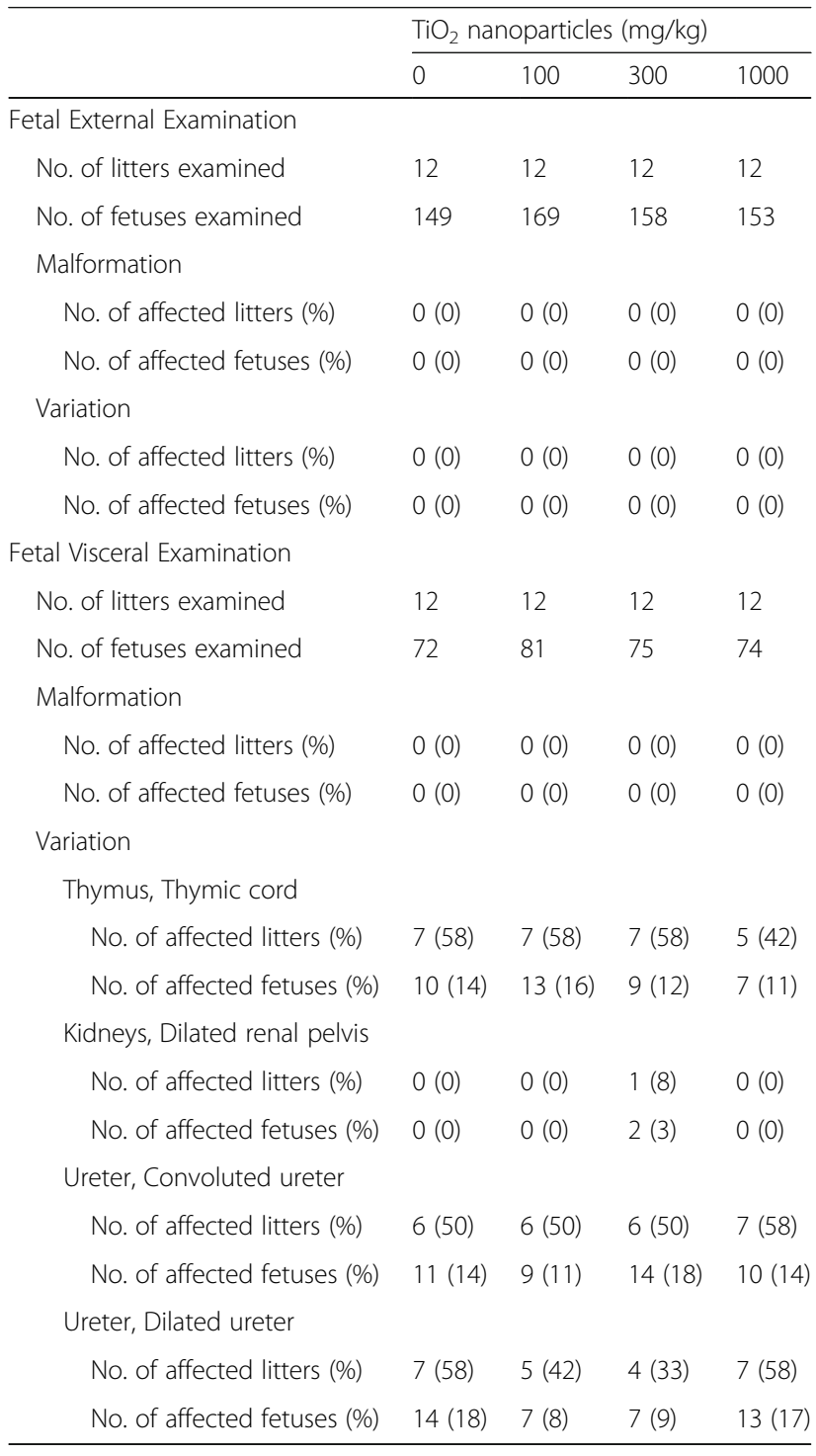

histopathological examination [14]. A repeated oral toxicity study in rats $(<50 \mathrm{~nm} ; 0.16,0.4$ and $1 \mathrm{~g} / \mathrm{kg}$ for 14 days) revealed disturbances in metabolism and the gut microflora environment caused by slight injury to the liver and heart, as shown by urianalysis with nuclear magnetic resonance (NMR) [35]. The results from other experimental animal studies indicated that the absorption of $\mathrm{TiO}_{2}$ nanoparticles is able to enter the systemic circulation and induce organ injuries and inflammation [12].

Reproductive and developmental toxicity potentials of $\mathrm{TiO}_{2}$ nanoparticles were also reported in previous studies with zebrafish, mice and rats. In zebrafish studies, $\mathrm{TiO}_{2}$ nanoparticles $(20 \mathrm{~nm} ; 5 \mathrm{mg} / \mathrm{mL}, 21 \mathrm{~nm} ; 0.01,10$ and $1000 \mu \mathrm{g} / \mathrm{mL}$ and $240-280 \mathrm{~nm}$ in water; $0.1 \mu \mathrm{g} / \mathrm{mL}$ ) induced deformities in the cardiovascular system, premature hatching and impaired reproduction [36-38]. In addition, $\mathrm{TiO}_{2}$ nanoparticle $(25 \mathrm{~nm} ; 0.1 \mu \mathrm{g} / \mathrm{mL})$ exposure alone did not induce toxicological effects but enhanced the metabolism of pentachlorophenol (PCP) and caused oxidative damage and developmental toxicity when co-exposed with PCP [39]. In mouse studies, subcutaneous $\mathrm{TiO}_{2}$ nanoparticle exposure $(2570 \mathrm{~nm} ; 100 \mu \mathrm{l}$ suspended at $1 \mu \mathrm{g} / \mu \mathrm{l}$; GDs $6,9,12.15$ and $25,70 \mathrm{~nm} ; 16$ $\mathrm{mg} / \mathrm{kg}$; GDs 3, 7, 10 and 14) during pregnancy induced genital and cranial nerve system damage in the offspring and altered gene expression in the brain during the prenatal period $[15,16]$. Intravenous $\mathrm{TiO}_{2}$ nanoparticle (35 $\mathrm{nm} ; 0.8 \mathrm{mg} /$ animal; GDs 16 and 17) exposure during pregnancy induced smaller uteri and fetuses, and $\mathrm{TiO}_{2}$ nanoparticles were found in the placenta, fetal liver and fetal brain [40]. In contrast, Warheit et al. [17] reported that oral exposure to different sized $\mathrm{TiO}_{2}$ particles (42, 43, 47, 153, 195 and $213 \mathrm{~nm} ; 100,300$, and $1000 \mathrm{mg} / \mathrm{kg}$; daily beginning on GDs 6 through 20 in rats) did not induce toxicities during pregnancy. Our study results confirmed that oral exposure to $\mathrm{TiO}_{2}$ nanoparticles during pregnancy did not induce toxic effects in maternal animals or embryo-fetal development endpoints. This finding is consistent with the study reported by Warheit et al. [17], although the analyzed primary particle size of the $\mathrm{TiO}_{2}$ nanoparticles was different from that in the previous study.

This discrepancy in reproductive and developmental results among previous studies is considered to be caused by differences in exposure routes, animal species, physicochemical properties of the nanoparticles, etc. In fact, a gastrointestinal absorption study of silver nanoparticles reported that nanoparticles were aggregated and changed their physical properties in the stomach, and the degree of these changes was especially influenced by the particle size of the nanoparticles [41]. This study indicates that oral exposure to nanoparticles is able to alleviate the toxicity by inducing the loss of characteristic properties of nanoparticles before they enter the systemic circulation when compared to directly systemically exposed routes, such as intravenous and inhalation routes. Quantitative biokinetics of $\mathrm{TiO}_{2}$ nanoparticle studies with oral and intravenous exposure also proved that internal exposure was much higher with intravenous than with oral exposure [42, 43]. These differences in internal exposure might result in different interactions and binding to blood proteins and biomolecules with $\mathrm{TiO}_{2}$ nanoparticles, which will subsequently affect uptake in organs and tissues [44]. Moreover, species differences in metabolism and placentation are considered to be important factors for birth defects occurrence [45]. In fact, the birth defect levels for selected developmental toxicants differ among animal species and humans [46]. 
Table 8 Fetal skeletal examination results of $\mathrm{TiO}_{2}$ nanoparticles exposed pregnant females during the pregnancy

\begin{tabular}{|c|c|c|c|c|}
\hline & \multicolumn{4}{|c|}{$\mathrm{TiO}_{2}$ nanoparticles $(\mathrm{mg} / \mathrm{kg})$} \\
\hline & 0 & 100 & 300 & 1000 \\
\hline \multicolumn{5}{|l|}{ Fetal Skeletal Examination } \\
\hline No. of litters examined & 12 & 12 & 12 & 12 \\
\hline No. of fetuses examined & 77 & 88 & 83 & 79 \\
\hline \multicolumn{5}{|l|}{ Malformation } \\
\hline No. of affected litters (\%) & $0(0)$ & $0(0)$ & $0(0)$ & $0(0)$ \\
\hline No. of affected fetuses (\%) & $0(0)$ & $0(0)$ & $0(0)$ & $0(0)$ \\
\hline \multicolumn{5}{|l|}{ Variation } \\
\hline \multicolumn{5}{|l|}{ Ribs, Full thoracic supernumerary rib } \\
\hline No. of affected litters (\%) & $0(0)$ & $2(17)$ & $0(0)$ & $0(0)$ \\
\hline No. of affected fetuses (\%) & $0(0)$ & $2(2)$ & $0(0)$ & $0(0)$ \\
\hline \multicolumn{5}{|l|}{ Ribs, Short thoracic supernumerary rib } \\
\hline No. of affected litters (\%) & $2(17)$ & $4(33)$ & $3(25)$ & $2(17)$ \\
\hline No. of affected fetuses (\%) & $5(6)$ & $9(10)$ & $4(5)$ & $2(2)$ \\
\hline \multicolumn{5}{|l|}{ Skull, Large fontanelle } \\
\hline No. of affected litters (\%) & $3(25)$ & $2(17)$ & $0(0)$ & $0(0)$ \\
\hline No. of affected fetuses (\%) & $4(5)$ & $2(2)$ & $0(0)$ & $0(0)$ \\
\hline \multicolumn{5}{|c|}{ Thoracic centrum, Asymmetric ossification } \\
\hline No. of affected litters (\%) & $0(0)$ & $0(0)$ & $1(8)$ & $0(0)$ \\
\hline No. of affected fetuses (\%) & $0(0)$ & $0(0)$ & $1(1)$ & $0(0)$ \\
\hline \multicolumn{5}{|c|}{ Thoracic centrum, Bipartite ossification } \\
\hline No. of affected litters (\%) & $0(0)$ & $0(0)$ & $1(8)$ & $2(17)$ \\
\hline No. of affected fetuses (\%) & $0(0)$ & $0(0)$ & $2(2)$ & $3(4)$ \\
\hline \multicolumn{5}{|c|}{ Thoracic centrum, Dumbbell ossification } \\
\hline No. of affected litters (\%) & $2(17)$ & $1(8)$ & $0(8)$ & $2(17)$ \\
\hline No. of affected fetuses (\%) & $3(3)$ & $1(1)$ & $0(0)$ & $2(3)$ \\
\hline \multicolumn{5}{|l|}{ No. of ossification centers } \\
\hline Sternebra & $5.9 \pm 0.18^{\mathrm{a}}$ & $5.9 \pm 0.20$ & $6.0 \pm 0.08$ & $5.8 \pm 0.30$ \\
\hline Metacarpals in both forelimbs & $7.8 \pm 0.38$ & $8.0 \pm 0.14$ & $8.0 \pm 0.12$ & $7.9 \pm 0.12$ \\
\hline 1st phalanges in both forelimbs & $1.8 \pm 1.39$ & $2.7 \pm 1.20$ & $2.1 \pm 1.12$ & $2.6 \pm 1.12$ \\
\hline Metatarsals in both hindlimbs & $8.0 \pm 0.09$ & $8.3 \pm 0.38^{* *}$ & $8.0 \pm 0.09$ & $8.0 \pm 0.03$ \\
\hline 1st phalanges in both hindlimbs & $0.2 \pm 0.58$ & $0.1 \pm 0.20$ & $0.0 \pm 0.06$ & $0.0 \pm 0.00$ \\
\hline Cervical vertebra & $1.3 \pm 1.29$ & $1.3 \pm 1.00$ & $1.4 \pm 1.23$ & $0.9 \pm 0.86$ \\
\hline Sacral and caudal vertebra & $8.5 \pm 0.45$ & $8.7 \pm 0.49$ & $8.5 \pm 0.50$ & $8.5 \pm 0.34$ \\
\hline
\end{tabular}

${ }^{a}$ Values are presented as mean \pm S.D

${ }^{* *}$ Significant difference at $p<0.01$ level compared with the control group

The distribution analysis of maternal and fetal tissues in this study showed that $\mathrm{TiO}_{2}$ nanoparticles were retained in the maternal liver, maternal brain and placenta at $1000 \mathrm{mg} / \mathrm{kg}$ after repeated oral exposure during pregnancy. At $300 \mathrm{mg} / \mathrm{kg}$, the $\mathrm{TiO}_{2}$ nanoparticle level was also slightly elevated in the maternal brain and placenta. However, it was indiscernible in the maternal blood, fetal liver, fetal brain and fetal blood of all the $\mathrm{TiO}_{2}$ nanoparticle-treated groups. Other studies have also reported that $\mathrm{TiO}_{2}$ nanoparticles can be absorbed into the systemic circulation and then distributed to internal organs. Single oral exposure of different sized $\mathrm{TiO}_{2}$ particles $(25,80$, and $155 \mathrm{~nm} ; 5 \mathrm{~g} / \mathrm{kg})$ in mice yielded retention of the particles in the liver, spleen, kidneys, brain and lung, but there was no detection of the particles in blood. The distribution level in each tissue varied depending on the $\mathrm{TiO}_{2}$ particle size [14]. Another single oral exposure study of $\mathrm{TiO}_{2}$ nanoparticles $(70 \mathrm{~nm}$; $30-80 \mu \mathrm{g} / \mathrm{kg}$ ) in rats reported that the $\mathrm{TiO}_{2}$ particles that crossed the intestinal membrane accounted for less than 


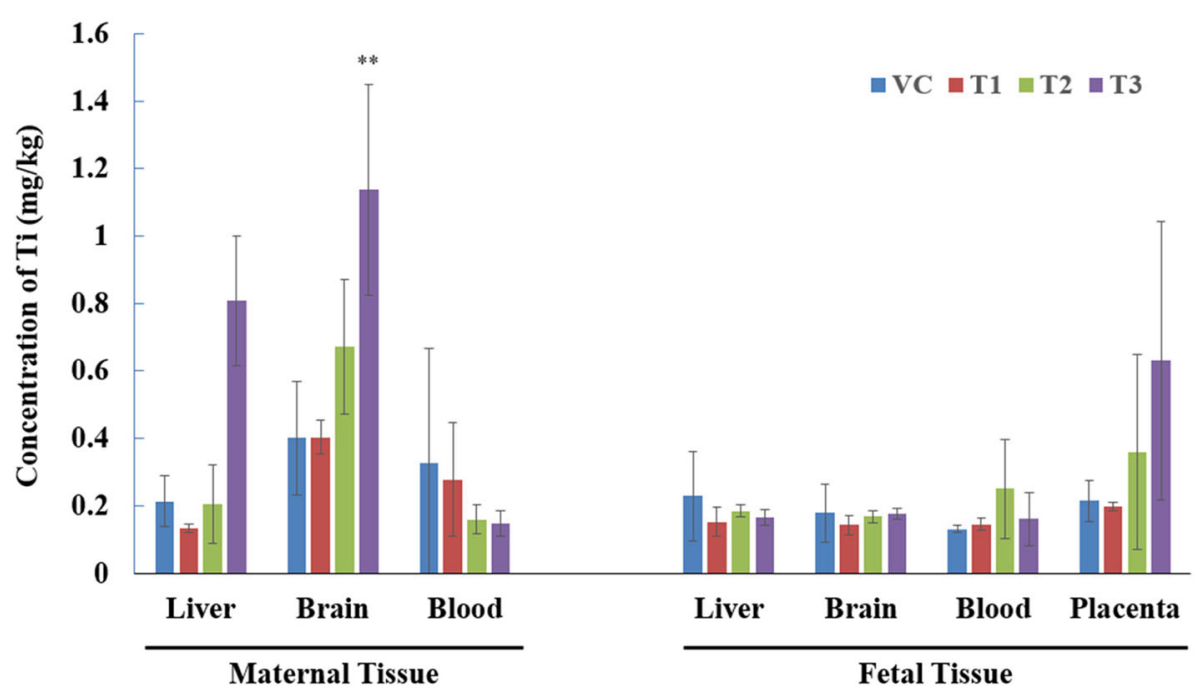

Fig. 1 The contents of titanium in maternal and fetal tissues after orally exposed $\mathrm{TiO}_{2}$ nanoparticles during the pregnancy. Values are presented as mean \pm S.D. $\left(n=3\right.$ or 4). VC; vehicle control, T1-3; 100, 300, and $1000 \mathrm{mg} / \mathrm{kg} \mathrm{TiO}_{2}$ nanoparticles groups. **Significant difference at $p<0.01$ level compared with the control group

$0.6 \%$ of the applied dose; however, the $\mathrm{TiO}_{2}$ particles were still distributed in the liver, lungs, kidneys, brain, spleen, uterus and skeleton after 7 days of exposure [43]. A single intravenous administration study of $\mathrm{TiO}_{2}$ nanoparticles $(20-30 \mathrm{~nm} ; 5 \mathrm{mg} / \mathrm{kg})$ in rats reported that the nanoparticles were mainly retained in the liver as well as the spleen and kidney but were not detected in the blood, brain and lymph nodes [47]. A single intraperitoneal administration of $\mathrm{TiO}_{2}$ nanoparticles $(100 \mathrm{~nm}$; 324$2592 \mathrm{mg} / \mathrm{kg}$ ) in mice yield retention in the spleen as well as liver, kidney and lung, but nanoparticles were not detected in the heart. The distribution level was changed depending on the sample collection time after administration [48]. These $\mathrm{TiO}_{2}$ nanoparticle distribution studies concluded that the liver and kidney were the most commonly observed internal organs into which the particles were distributed after they were absorbed into the systemic circulation regardless of the administration route and particle size. However, it was also concluded that the $\mathrm{TiO}_{2}$ nanoparticle distribution can change depending on the administration route, particle size and tissue sampling time.

One intriguing distribution result in this study was the relatively high level of $\mathrm{TiO}_{2}$ nanoparticles detected in the brain. Distribution studies of $\mathrm{TiO}_{2}$ nanoparticles in the brain have not been comprehensively conducted, but several studies have suggested that $\mathrm{TiO}_{2}$ nanoparticles can be deposited into the brain. Wang et al. [14] reported that acute orally exposed $\mathrm{TiO}_{2}$ particles $(25,80$ and $155 \mathrm{~nm} ; 5 \mathrm{~g} / \mathrm{kg}$ ) in mice were deposited in the brain and induced fatty degeneration in the hippocampus. Li et al. [49] also reported that intratracheal instillation of $\mathrm{TiO}_{2}$ particles $(3 \mathrm{~nm} ; 13.2 \mathrm{mg} / \mathrm{kg}$, once a week for 4 weeks) in mice induced brain injury through oxidative stress. Taken together, these previous studies indicate that $\mathrm{TiO}_{2}$ nanoparticles are able to penetrate the bloodbrain barrier, and these results were consistent with our study results.

No marked toxicities were observed in maternal animals and embryo-fetal development in this study design, but this finding does not indicate that $\mathrm{TiO}_{2}$ nanoparticles are completely safe during pregnancy. Generally, two species (commonly rats and rabbits) are required in this type of study to evaluate toxicity during pregnancy [50]. In fact, rats and rabbits might be able to exhibit different teratogenic results during pregnancy [45]. Moreover, it is noteworthy that $\mathrm{TiO}_{2}$ nanoparticles $(75 \mathrm{~nm}$; 10,50 and $200 \mathrm{mg} / \mathrm{kg}$; daily oral for 30 days) are able to induce liver edema (revealed by histopathological examination) and reductive stress (shown by biochemical assays) [51]. This result indicates that the toxicity of $\mathrm{TiO}_{2}$ nanoparticles can be detected by more sensitive and/or different parameters. In this regard, additional reproductive endpoints, including fertility, parturition, postnatal development and hormone analysis, were not investigated, and these parameters will support the accurate safety assessment of $\mathrm{TiO}_{2}$ nanoparticles. Considering the possibility of complex $\mathrm{TiO}_{2}$ nanoparticles exposure scenarios and their various particle sizes, it is necessary to conduct additional studies to evaluate the potential adverse effects of $\mathrm{TiO}_{2}$ nanoparticles.

In conclusion, we systemically investigated the maternal and embryo-fetal effects of orally exposed $\mathrm{TiO}_{2}$ nanoparticles during pregnancy in rats. In addition, we analyzed the titanium distribution during pregnancy using maternal and fetal tissues. As a result, there were 
no $\mathrm{TiO}_{2}$ nanoparticle-related toxicity findings in maternal animals or with respect to embryo-fetal development in this study design, and the titanium content was increased in the maternal liver, maternal brain and placenta with high-dose exposure to $\mathrm{TiO}_{2}$ nanoparticles. The results of this study can be used to evaluate the human risk assessment of $\mathrm{TiO}_{2}$ nanoparticles during pregnancy, and additional toxicity studies are considered necessary to elucidate the effects of $\mathrm{TiO}_{2}$ nanoparticles under various exposure scenarios and at different particle sizes.

\section{Abbreviations \\ AAALAC: Association for Assessment and Accreditation of Laboratory Animal Care International; ANCOVA: Analysis of covariance; ANOVA: Analysis of variance; BET: Brunauer-Emmett-Teller; GD: Gestation day; GLP: Good laboratory practice; $\mathrm{H}_{2} \mathrm{O}_{2}$ : Hydrogen peroxide; HF: Hydrofluoric acid; $\mathrm{HNO}_{3}$ : Nitric acid; IACUC: Institutional Animal Care and Use Committee; ICP- MS: Inductively coupled plasma mass spectrometry; IDL: Instrumental detection limits; LAR: Institute for Laboratory Animal Research; LOQ: Limit of quantification; MDL: Method detection limits; PCP: Pentachlorophenol; ROS: Reactive oxygen species; SPF: Specific pathogen free; $\mathrm{TiO}_{2}$ : Titanium dioxide}

\section{Acknowledgments}

The authors would like to especially thank the technical staff of the developmental and reproductive toxicology research group at KIT for their technical support.

\section{Authors' contributions}

$J \mathrm{~L}, \mathrm{KP}, \mathrm{SYN}$ and WJY conceived and designed the present study. JL, JSJ and SYK conducted the animal experiments, and MKP, SDC and UJK conducted the titanium distribution analysis. JL and JSJ analyze the physicochemical properties of particles. JL and WJY interpreted the data and wrote the manuscript. All authors reviewed and approved the final manuscript.

\section{Funding}

This work was supported by the National Institute of Environmental Research (Grant No. NIER-SP2012-176).

\section{Availability of data and materials}

The relevant datasets supporting the conclusions of this article are included within the article, and all datasets used and analyzed during the current study are available from the corresponding author on reasonable request.

\section{Ethics approval and consent to participate}

All animal protocols were prepared in accordance with the Animal Protection Act of Korea and Guide for the Care and Use of Laboratory Animals published by the Institute for Laboratory Animal Research (ILAR). This animal study was approved by the Institutional Animal Care and Use Committee (IACUC) of KIT.

\section{Consent for publication}

Not applicable.

\section{Competing interests}

The authors declare that they have no competing interests.

\section{Author details}

'Developmental and Reproductive Toxicology Research Group, Korea Institute of Toxicology, Deajeon 34114, Republic of Korea. ${ }^{2}$ College of Veterinary Medicine, Chungbuk National University, Cheongju, Republic of Korea. ${ }^{3}$ School of Urban and Environmental Engineering, Ulsan National Institute of Science and Technology, Ulsan, Republic of Korea. ${ }^{4}$ UNIST Environmental Analysis Center (UEAC), Ulsan National Institute of Science and Technology, Ulsan, Republic of Korea. ${ }^{5}$ College of Pharmacy, Dongduk Women's University, Seoul, Republic of Korea.
Received: 23 January 2019 Accepted: 2 July 2019

Published online: 18 July 2019

\section{References}

1. Sargent JF. Nanotechnology: a policy primer; 2012.

2. Penn SG, He L, Natan MJ. Nanoparticles for bioanalysis. Curr Opin Chem Biol. 2003;7:609-15.

3. Liu WT. Nanoparticles and their biological and environmental applications. J Biosci Bioeng. 2006;102:1-7.

4. European Commission Communication from the Commision to the European Parliament, the Council and the European Economic and Social Committee. Second Regulatory Review on Nanomaterials. COM(2012) 572final; 2012. p. 1-15.

5. Rothen-Rutishauser B, Schürch S, Gehr P. Interaction of particles with membranes. In: Donaldson K, Borm P, editors. Paticle toxicology. Boca Raton: CRC Press; 2007. p. 139-60.

6. Hansen SF, Michelson ES, Kamper A, Borling P, Stuer-Lauridsen F, Baun A. Categorization framework to aid exposure assessment of nanomaterials in consumer products. Ecotoxicology. 2008;17:438-47.

7. Hendren CO, Mesnard X, Dröge J, Wiesner MR. Estimating production data for five engineered nanomaterials as a basis for exposure assessment. Environ Sci Technol. 2011;45:2562-9.

8. Baan R, Straif K, Grosse Y, Secretan B, El Ghissassi F, Cogliano V. Carcinogenicity of carbon black, titanium dioxide, and talc. Lancet Oncol. 2006;:295-6

9. Kaida T, Kobayashi K, Adachi M, Suzuki F. Optical characteristics of titanium oxide interference film and the film laminated with oxides and their applications for cosmetics. J Cosmet Sci. 2004;55:219-20.

10. Wang JJ, Sanderson BJ, Wang H. Cyto- and genotoxicity of ultrafine $\mathrm{TiO} 2$ particles in cultured human lymphoblastoid cells. Mutat Res. 2007; 628:99-106

11. Wolf $\mathrm{R}$, Matz H, Orion E, Lipozencic J. Sunscreens-the ultimate cosmetic. Acta Dermatovenerol Croat. 2003;11:158-62.

12. Shakeel M, Jabeen F, Shabbir S, Asghar MS, Khan MS, Chaudhry AS. Toxicity of nano-titanium dioxide (TiO2-NP) through various routes of exposure: a review. Biol Trace Elem Res. 2016;172(1):1-36.

13. Lomer MC, Thompson RP, Powell JJ. Fine and ultrafine particles of the diet: influence on the mucosal immune response and association with Crohn's disease. Proc Nutr Soc. 2002;61(1):123-30.

14. Wang J, Zhou G, Chen C, Yu H, Wang T, Ma Y, et al. Acute toxicity and biodistribution of different sized titanium dioxide particles in mice after oral administration. Toxicol Lett. 2007;168(2):176-85.

15. Shimizu M, Tainaka H, Oba T, Mizuo K, Umezawa M, Takeda K. Maternal exposure to nanoparticulate titanium dioxide during the prenatal period alters gene expression related to brain development in the mouse. Part Fibre Toxicol. 2009;6(1):20.

16. Takeda K, Suzuki K, Ishihara A, Kubo-lrie M, Fujimoto R, Tabata M, et al. Nanoparticles transferred from pregnant mice to their offspring can damage the genital and cranial nerve system. J Health Sci. 2009;55:95-102.

17. Warheit DB, Boatman R, Brown SC. Developmental toxicity studies with 6 forms of titanium dioxide test materials ( 3 pigment-different grade \& 3 nanoscale) demonstrate an absence of effects in orally-exposed rats. Regul Toxicol Pharmacol. 2015;73(3):887-96.

18. OECD Guideline for the testing of chemicals, prenatal developmental toxicity study, OECD 414, adopted $22^{\text {nd }}$ January 2001, http://www.oecd.org/ chemicalsafety/risk-assessment/1948482.pdf.

19. Wilson JG. Methods for administering agents and detecting malformations in experimental animals. In: Wilson JG, Warkany J, editors. Teratology, principles and techniques. Chicago and London: University of Chicago Press; 1965.

20. Nishimura K. A microdissection method for detecting thoracic visceral malformations in mouse and rat fetuses. Cong Anom. 1974;14:23-40.

21. Staples RE. Detecting of visceral alterations in mammalian fetuses. Teratology. 1974;9:37-8.

22. Dawson AB. A note on the staing of the skeleton of cleared specimens with alizarin red. S Stain Technol. 1926;1:123-4.

23. Makris SL, Solomon HM, Clark R, Shiota K, Barbellion S, Buschmann J, Ema M, Fujiwara M, Grote K, Hazelden KP, Hew KW, Horimoto M, Ooshima Y, Parkinson M, Wise LD. Terminology of developmental abnormalities in common laboratory mammals (version 2). Birth Defects Res B. 2009;86:227-327. 
24. Bortey-Sam N, Nakayama SMM, Ikenaka Y, Akoto O, Baidoo E, Mizukawa H, Ishizuka M. Heavy metals and metalloid accumulation in livers and kidneys of wild rats around gold-mining communities in Tarkwa, Ghana. J Environ Chem Ecotoxicol. 2016;8(7):58-68.

25. Devoy J, Brun E, Cosnefroy A, Disdier C, Melczer M, Antoine G, Chalansonnet M, Mabondzo A. Mineralization of $\mathrm{TiO}_{2}$ nanoparticles for the determination of titanium in rat tissues. J Anal Chem. 2016;71(4):418-25.

26. Krystek P, Tentschert J, Nia Y, Trouiller B, Noël L, Goetz ME, Papin A, Luch A, Guérin T, De Jong WH. Method development and inter-laboratory comparison about the determination of titanium from titanium dioxide nanoparticles in tissues by inductively coupled plasma mass spectrometry. Anal Bioanal Chem. 2014;406(16):3853-61.

27. Bhattacharya K, Davoren M, Boertz J, Schins RP, Hoffmann E, Dopp E. Titanium dioxide nanoparticles induce oxidative stress and DNA-adduct formation but not DNA-breakage in human lung cells. Part Fibre Toxicol. 2009;6(1):17.

28. Kang SJ, Kim BM, Lee YJ, Chung HW. Titanium dioxide nanoparticles trigger p53-mediated damage response in peripheral blood lymphocytes. Environ Mol Mutagen. 2008;49(5):399-405.

29. Shi H, Magaye R, Castranova V, Zhao J. Titanium dioxide nanoparticles: a review of current toxicological data. Part Fibre Toxicol. 2013;10(1):15.

30. Yazdi AS, Guarda G, Riteau N, Drexler SK, Tardivel A, Couillin I, Tschopp J. Nanoparticles activate the NLR pyrin domain containing 3 (Nlrp3) inflammasome and cause pulmonary inflammation through release of IL-1a and IL-1ß. Proc Natl Acad Sci. 2010;107(45):19449-54.

31. Morishige T, Yoshioka Y, Tanabe A, Yao X, Tsunoda SI, Tsutsumi Y, et al. Titanium dioxide induces different levels of $I L-1 \beta$ production dependent on its particle characteristics through caspase- 1 activation mediated by reactive oxygen species and cathepsin B. Biochem Biophys Res Commun. 2010; 392(2):160-5.

32. Gui S, Zhang Z, Zheng L, Cui Y, Liu X, Li N, et al. Molecular mechanism of kidney injury of mice caused by exposure to titanium dioxide nanoparticles. J Hazard Mater. 2011;195:365-70.

33. Shukla RK, Sharma V, Pandey AK, Singh S, Sultana S, Dhawan A. ROSmediated genotoxicity induced by titanium dioxide nanoparticles in human epidermal cells. Toxicol in Vitro. 2011;25(1):231-41.

34. Driscoll KE, Deyo LC, Carter JM, Howard BW, Hassenbein DG, Bertram TA Effects of particle exposure and particle-elicited inflammatory cells on mutation in rat alveolar epithelial cells. Carcinogenesis. 1997;18(2):423-30.

35. Bu Q, Yan G, Deng P, Peng F, Lin H, Xu Y, et al. NMR-based metabonomic study of the sub-acute toxicity of titanium dioxide nanoparticles in rats after oral administration. Nanotechnology. 2010;21(12):125105.

36. Xu Z, Zhang YL, Song C, Wu LL, Gao HW. Interactions of hydroxyapatite with proteins and its toxicological effect to zebrafish embryos development. PLoS One. 2012;7(4):e32818.

37. Samaee SM, Rabbani S, Jovanović B, Mohajeri-Tehrani MR, Haghpanah V. Efficacy of the hatching event in assessing the embryo toxicity of the nanosized $\mathrm{TiO}_{2}$ particles in zebrafish: a comparison between two different classes of hatching-derived variables. Ecotoxicol Environ Saf. 2015;116:121-8.

38. Wang J, Zhu X, Zhang X, Zhao Z, Liu H, George R, et al. Disruption of zebrafish (Danio rerio) reproduction upon chronic exposure to $\mathrm{TiO}_{2}$ nanoparticles. Chemosphere. 2011;83(4):461-7.

39. Fang Q, Shi X, Zhang L, Wang Q, Wang X, Guo Y, Zhou B. Effect of titanium dioxide nanoparticles on the bioavailability, metabolism, and toxicity of pentachlorophenol in zebrafish larvae. J Hazard Mater. 2015;283:897-904.

40. Yamashita K, Yoshioka Y, Higashisaka K, Mimura K, Morishita Y, Nozaki M, et al. Silica and titanium dioxide nanoparticles cause pregnancy complications in mice. Nat Nanotechnol. 2011;6(5):321-8.

41. Mwilu SK, El Badawy AM, Bradham K, Nelson C, Thomas D, Scheckel KG, et al. Changes in silver nanoparticles exposed to human synthetic stomach fluid: effects of particle size and surface chemistry. Sci Total Environ. 2013;447:90-8.

42. Geraets L, Oomen AG, Krystek P, Jacobsen NR, Wallin H, Laurentie M, et al. Tissue distribution and elimination after oral and intravenous administration of different titanium dioxide nanoparticles in rats. Part Fibre Toxicol. 2014;1 1(1):30.

43. Kreyling WG, Holzwarth U, Schleh C, Kozempel J, Wenk A, Haberl N, et al. Quantitative biokinetics of titanium dioxide nanoparticles after oral application in rats: part 2. Nanotoxicology. 2017;11(4):443-53.

44. Kreyling WG, Holzwarth U, Haberl N, Kozempel J, Hirn S, Wenk A, et al. Quantitative biokinetics of titanium dioxide nanoparticles after intravenous injection in rats: part 1. Nanotoxicology. 2017;11(4):434-42.

45. Carney EW, Tornesi B, Markham DA, Rasoulpour RJ, Moore N. Speciesspecificity of ethylene glycol-induced developmental toxicity: toxicokinetic and whole embryo culture studies in the rabbit. Birth Defects Res B Dev Reprod Toxicol. 2008;83(6):573-81.

46. Kimmel CA, Holson JF, Hogue Cl, Carlo GL. Reliability of experimental studies for predicting hazards to human development. Jefferson, Arkansas: U.S. Food and Drug Administration, National Center for Toxicological Research, NCTR technical report for experiment No. 6015; 1984.

47. Fabian E, Landsiedel R, Ma-Hock L, Wiench K, Wohlleben W, Van Ravenzwaay B. Tissue distribution and toxicity of intravenously administered titanium dioxide nanoparticles in rats. Arch Toxicol. 2008;82(3):151-7.

48. Chen J, Dong X, Zhao J, Tang G. In vivo acute toxicity of titanium dioxide nanoparticles to mice after intraperitioneal injection. J Appl Toxicol. 2009; 29(4):330-7

49. Li Y, Li J, Yin J, Li W, Kang C, Huang Q, Li Q. Systematic influence induced by $3 \mathrm{~nm}$ titanium dioxide following intratracheal instillation of mice. J Nanosci Nanotechnol. 2010;10(12):8544-9.

50. Wise LD, Buschmann J, Feuston MH, Fisher JE, Hew KW, Hoberman AM, et al. Embryo-fetal developmental toxicity study design for pharmaceuticals. Birth Defects Res B Dev Reprod Toxicol. 2009;86(6):418-28.

51. Wang Y, Chen Z, Ba T, Pu J, Chen T, Song Y, et al. Susceptibility of young and adult rats to the oral toxicity of titanium dioxide nanoparticles. Small. 2013;9(9-10):1742-52.

\section{Publisher's Note}

Springer Nature remains neutral with regard to jurisdictional claims in published maps and institutional affiliations.
Ready to submit your research? Choose BMC and benefit from:

- fast, convenient online submission

- thorough peer review by experienced researchers in your field

- rapid publication on acceptance

- support for research data, including large and complex data types

- gold Open Access which fosters wider collaboration and increased citations

- maximum visibility for your research: over $100 \mathrm{M}$ website views per year

At BMC, research is always in progress.

Learn more biomedcentral.com/submissions 